Supporting Information

\title{
Direct Observation of the Protonation States in the Mutant Green Fluorescent Protein
}

Chie Shibazaki, $†$ Rumi Shimizu, $†$ Yuji Kagotani, $†$ Andreas Ostermann, $\S$ Tobias E. Schrader, $\Varangle$

Motoyasu Adachi, ${ }^{*}, \dagger$

$\dagger$ Institute for Quantum Life Science, National Institutes for Quantum and Radiological Science and

Technology (QST), 2-4 Shirakata, Tokai, Ibaraki, 319-1106, Japan

$\S$ Heinz Maier-Leibnitz Zentrum (MLZ), Technische Universität München, Lichtenbergstrasse 1, 85748

Garching, Germany

$\ddagger$ Jülich Centre for Neutron Science (JCNS) at Heinz Maier-Leibnitz Zentrum (MLZ), Forschungszentrum

Jülich GmbH, Lichtenbergstrasse 1, 85748 Garching, Germany

*Correspondence to: adachi.motoyasu@qst.go.jp 
Table of Contents

Item

Materials and Methods

Supplementary Figure S1: The chemically-synthesized DNA and amino acid sequences for EGFPq.

Supplementary Figure S2: $\quad$ Amino acid sequence alignment of wild-type and mutant GFP proteins.

Supplementary Figure S3: Photo of a large crystal of EGFPq used for neutron diffraction data collection at FRMII.

Supplementary Figure S4: The tertiary structure of EGFPq determined by neutron crystallography.

Supplementary Figure S5: Absorption and fluorescent spectra of the EGFPq and GFPq.

Supplementary Figure S6: Neutron crystal structure of the His148 residue in EGFPq.

Supplementary Figure S7: Neutron scattering density maps of deuterium atoms for thirty water molecules.

Supplementary Table S1: Data collection and refinement statistics of neutron and X-ray crystallography.

Supplementary Table S2: Chemical bond lengths in chromophore for GFP proteins solved by high resolution X-ray crystallography.

Supplementary Table S3: Bond distances in water molecules for EGFPq with restraint and unrestraint refinements by using slack value.

Supplementary Table S4: $\quad$ OH bond distances in hydronium ion and Glu17 for EGFPq refined by using slack value.

Supplementary Table S5: $\quad$ DNA primer sequences for EGFP and GFP mutants.

Supplementary Table S6. The coordinates obtained by the unrestraint refinement and displaced according to the neutron omit maps.

Supplementary References 


\section{Materials \& Methods}

\section{Construction of Expression Plasmids for Mutant GFPs}

The chemically-synthesized DNA encoding the gene from the initial methionine to Lys238 including Q80R and I167T mutations was purchased from Operon Biotechnologies Inc. (Japan), as optimized for E.coli. The synthesized DNA was inserted into the pET24a vector by using In-Fusion HD Enzyme (Takara Bio, Japan) (Figure S1). The four primers of GFP_fu_N2, GFP_fu_C2, pET24a_fusion_F, and pET24a_fusion_R2 were used for the sub-cloning into the vector (Table S4). Further mutations of C48S, N159Q, and S65T were introduced by using In-Fusion HD Enzyme and DNA primers of GFP_C48S_F, GFP_C48S_R, GFP_N159Q_F, GFP_N159Q_R, GFP_S65T_F, and GFP_S65T_R to produce EGFPq used in this study (The letter of q means the term of quantum). The construct for GFPq corresponding to wild-type was also prepared using the four primers of GFP_C48S_F, GFP_C48S_R, GFP_N159Q_F, and GFP_N159Q_R. The resulting plasmids were used for expression of the mutant EGFPq and GFPq in E.coli BL21(DE3). Plasmids were prepared using QIAprep Spin Miniprep Kit (Qiagen, CA). The DNA sequence coding for the proteins was confirmed by DNA sequencing on the ABI PRISM 310 Genetic Analyzer (Thermo Fisher Scientific, MA).

\section{Protein Expression and Purification for Mutant GFPs}

The bacterial cells were grown at $310 \mathrm{~K}$ in LB medium to an OD600 around 0.7, and protein expression was induced at $310 \mathrm{~K}$ for 18 hours by adding isopropyl- $\beta$-D-thiogalactopyranoside to a final concentration of $0.1 \mathrm{mM}$. The cells were suspended in 20 mM Tris-HCl buffer at pH 8.5 containing 1 mg/mL Lysozyme, 1\% Triton X-100, and $2 \mathrm{mM}$ dithiothreitol (DTT), and then disrupted by sonication. The cell lysate was centrifuged at $10,000 \mathrm{~g}$ for $30 \mathrm{~min}$. Because the target proteins were expressed as inclusion bodies, the pellet was suspended with $20 \mathrm{mM}$ Tris-HCl buffer (pH 8.5) containing $1 \mathrm{mM}$ DTT, and collected by centrifugation at $10,000 \mathrm{~g}$ for $30 \mathrm{~min}$. The pellet was washed two times, and solubilized in $8 \mathrm{M}$ urea containing $50 \mathrm{mM}$ DTT at $310 \mathrm{~K}$ for an hour. After centrifugation, the supernatant was 
diluted with vigorous stirring against $20 \mathrm{mM}$ Tris- $\mathrm{HCl}$ buffer (pH 8.0) containing $10 \%$ glycerol, $5 \%$ ethylene glycol, $0.5 \mathrm{M}$ arginine $\mathrm{HCl}$ and $50 \mathrm{mM} \mathrm{CaCl}_{2}$, and then stored overnight at $278 \mathrm{~K}$. The protein solution was dialysed against $20 \mathrm{mM}$ Tris-HCl buffer (pH 8.0) containing $1 \mathrm{mM}$ DTT (buffer T) overnight at $278 \mathrm{~K}$. After the insoluble materials were removed by centrifugation, the clear green supernatant was applied onto a HiTrap ${ }^{\mathrm{TM}} \mathrm{Q}$ XL column (GE Healthcare). The protein was eluted with a linear gradient of $0-1.0 \mathrm{M} \mathrm{NaCl}$ in the buffer $\mathrm{T}$. The pooled fraction containing EGFPs or GFPs was desalted with buffer T by dialysis. The final yield was $58.7 \mathrm{mg}$ for EGFPq from 1.5 L of culture. The protein concentration was determined using UV absorption at $280 \mathrm{~nm}$ with a molecular extinction coefficient of $20400 \mathrm{~cm}^{-1} \mathrm{M}^{-1}$ for crystallization [34].

\section{Preparation of Large Crystal for Neutron Crystallography}

The initial crystallization conditions for the EGFPq were surveyed by the hanging-drop vapor diffusion method with PEGRx HT (Hampton Research) at $293 \mathrm{~K}$. The protein solution of $20 \mathrm{mg} / \mathrm{ml}$ in $0.4 \mathrm{uL}$ was mixed with the same volume of reservoir solution containing $0.1 \mathrm{M}$ 2-(N-morpholino)ethanesulfonic acid (MES) buffer (pH 6.0) and 20\% w/v polyethylene glycol (PEG) monomethyl ether 2000 (PEGRx No23). After optimizing crystallization conditions, larger crystals in size were obtained by mixing precipitant solution containing $0.1 \mathrm{M}$ MES buffer (pH 6.0), $12.0 \%$ w/v PEG 2000 and 50 mM non-detergent sulfobetain-201 (NDSB) (Calbiochem) (1.2 $\mu \mathrm{l})$, and $36 \mathrm{mg} / \mathrm{ml}$ protein solution in buffer $\mathrm{T}(0.8 \mu \mathrm{l})$. Next, to reduce the background noise level due to incoherent neutron scattering, the precipitant solution was exchanged with $\mathrm{D}_{2} \mathrm{O}$, and the crystallization condition was changed. The precipitant solution containing 0.1 M MES-NaOD (pD 7.0), $5.0 \%$ w/v PEG 2000 and $50 \mathrm{mM}$ NDSB (160 $\mu$ l) was mixed with $38 \mathrm{mg} / \mathrm{ml}$ protein solution in $20 \mathrm{mM}$ Tris-DCl buffer (pD 8.0) containing $1 \mathrm{mM}$ DTT (240 $\mu$ l). The mixture was bedded in a $350 \mu \mathrm{L}$ dialysis button (Hampton Research) and equilibrated against $4 \mathrm{ml}$ of the reservoir solution, which was composed of 0.1 M MES-NaOD (pD 7.0), 9.0 \% w/v PEG 2000 and $50 \mathrm{mM}$ NDSB at 293K. Eventually, a large crystal for EGFPq in size of $1.7 \mathrm{~mm}^{3}$ was obtained for 6 month incubation. Here, the solution of the large crystal was exchanged into the 
cryoprotectant solution composed of 0.1 M HEPES-NaOD (pD 7.5), 27\% w/v PEG 2000, and $15 \%$ w/v D-glycerol for 28 days.

\section{Neutron and X-Ray Diffraction Experiments}

The crystal was mounted with a cryoloop and flash-cooled in a nitrogen-gas stream at $100 \mathrm{~K}$ at the neutron diffractometer, BioDiff [14], installed at the Forschungs-Neutronenquelle Heinz Maier-Leibnitz FRM II (Garching, Germany). Neutron diffraction data were collected with a wavelength of $2.665 \AA$ at $100 \mathrm{~K}$ for two crystal orientations up to a resolution of $\mathrm{d}_{\min }=1.45 \AA$ using the rotation method. For the first orientation, 235 rotation frames were recorded with a rotation range of 0.3 degree per frame and an exposure time of $30 \mathrm{~min}$. For the second crystal orientation, 133 frames were collected with the same rotation range and exposure time. The collected data were indexed, integrated and scaled using HKL2000 and SCALEPACK programs [35].

After the neutron diffraction data were collected, X-ray diffraction data were obtained with the crystal prepared at the same conditions as that used for the neutron diffraction experiments. X-ray measurement was carried out at beamline BL5A in the KEK Photon Factory (Tsukuba, Japan). The dataset was collected using a monochromatic X-ray beam $(\lambda=1.00 \AA)$ at $100 \mathrm{~K}$. The oscillation angle was $1.0^{\circ}$ per image. A total of 180 images were collected. X-ray diffraction data were integrated and scaled using the HKL-2000 suite of programs [33]. Data collection and refinement statistics of neutron and X-ray diffraction studies are summarized in Table S1.

\section{Crystal Structure Determination}

Initial phase information for EGFPq was obtained from the structure previously reported (PDB id: 3WUR) [16]. The crystallographic refinement of the neutron structure was performed by the program PHENIX in a joint neutron and X-ray refinement with phenix.refine [15]. For the refinement in doubly protonated His148 including tetrahedral structure in ND2 atom, three parameters were introduced as follows; bond angles for DE2-NE2-CD2 and DE2-NE2-CD1 
are 109 degree, and DE2-NE2 bond distance is $1.020 \AA$. Neutron-scattering length density and electron density were visualized and manual model refinement was performed using XtalView [36]. The H/D exchange for main chain amide hydrogens was refined by occupancy refinement using the program PHENIX. For refinement of GFPq using X-ray diffraction, data analysis was also performed by the program PHENIX. Refinement statistics are summarized in Table S1. The figures were made using the program Pymol (http://www.pymol.org).

\section{Partially Unrestrained Refinement for Bond Length}

The slack values were changed for the unrestrained refinement in bond lengths. For example, the slack value of $0.5 \AA$ can make squared-well potential with the bottom size of $1.0 \AA$ in the well. The temporal bonds were formed between the unrestrained atom and surrounding atoms, for example, the acceptor atom in hydrogen bond to avoid steric hindrance. To estimate standard deviation of the unrestrained bond lengths, the final refinement structure was further refined by changing the ration of data for free $\mathrm{R}$ calculation ranging from 2 to $6 \%$ with $0.1 \%$ step. The standard deviation of bond lengths were estimated using all 41 refined structures. The average coordinate values for of D1 and D2 atoms in DOD323 and DE2 atoms in His148 are listed in Table S6.

\footnotetext{
Absorption and Fluorescent Measurements

UV/Vis absorption and fluorescence excitation spectra were recorded at room temperature with a model V-760 spectrophotometer (Nihon Bunko), and with a model FP-8300 fluorescence spectrometers (Nihon Bunko). The protein solutions in buffer $\mathrm{T}$ were illuminated with light centered at $460 \mathrm{~nm}$, and the fluorescence was detected. The protein concentrations were adjusted to $1 \mathrm{mg} / \mathrm{mL}$ by using TaKaRa BCA Protein Assay Kit (Takara Bio, Japan). The value of UV absorption at $280 \mathrm{~nm}$ was not used to compare efficiency production of chromophores.
} 


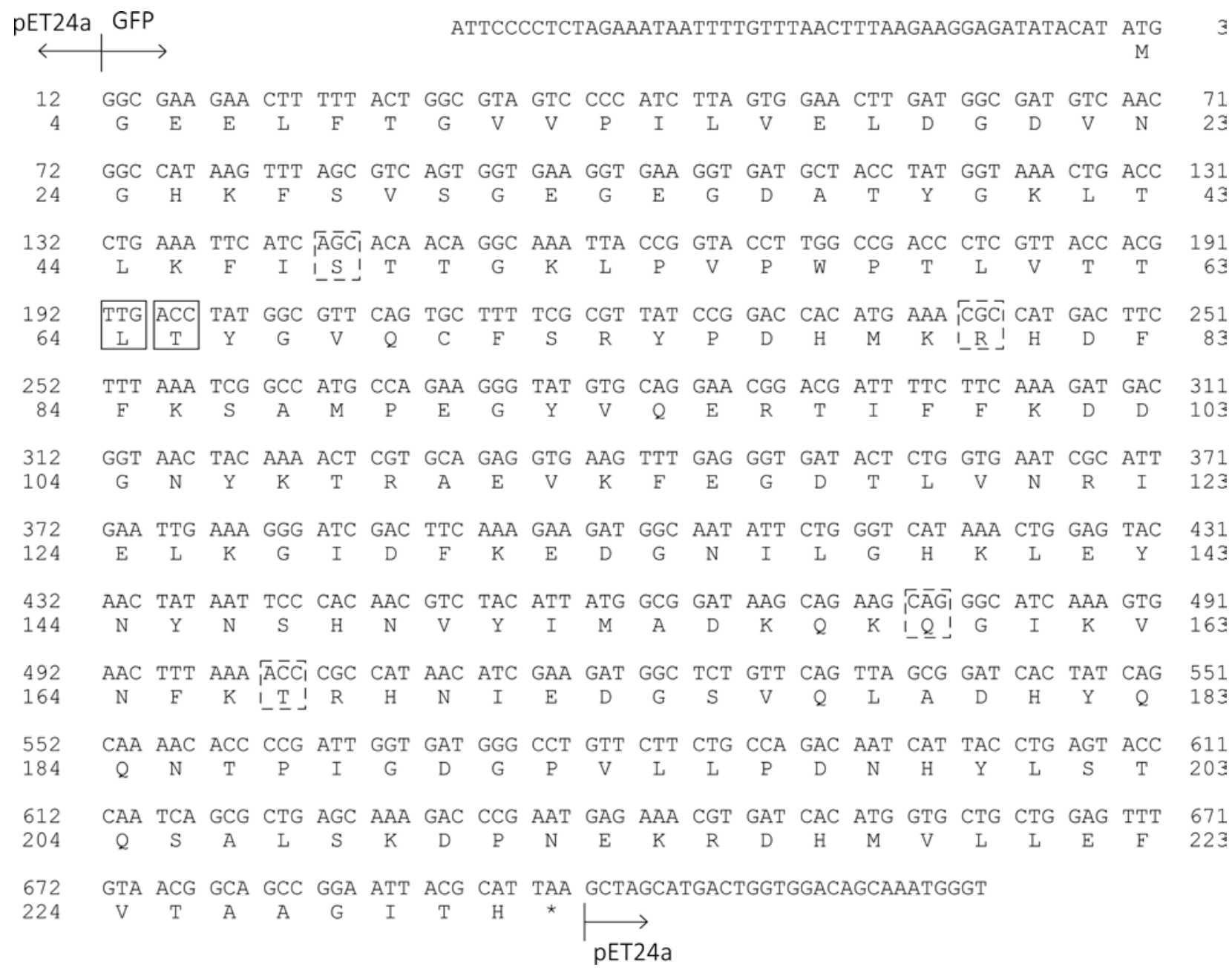

Figure S1. The chemically-synthesized DNA and amino acid sequences for EGFPq. The mutated sites for improvement of crystal packing are indicated by dashed squares (C48S, Q80R, N159Q, I167T). The two mutations of F64L and S65T corresponding to EGFP are shown in open squares. The original protein sequence was referred from the report by Prasher et al. [8]. The partial DNA sequences from vector of pET24a at the both sides of EGFPq are also shown. 


\begin{tabular}{|c|c|}
\hline 72 & FTGVVPILVELDGDVNGHKFSVSGEGEGDATYGKLTLKFICTTGKLPVPWPT \\
\hline 4EUL & KGEELFTGVVPILVELDGDVNGHKFSVSGEGEGDATYGKLTLKFICTTGKLPVPW \\
\hline EGFPq & MGEELFTGVVPILVELDGDVNGHKFSVSGEGEGDATYGKLTLKFISTTGKLPVPW \\
\hline GFPq & MGEELFTGVVPILVELDGDVNGHKFSVSGEGEGDATYGKLTLKFISTTGKLPVPW \\
\hline 2WUR & MSKGEELFTGVVPILVELDGDVNGHKFSVSGEGEGDATYGKLTLKFICTTGKLPVPW \\
\hline 6JGI & 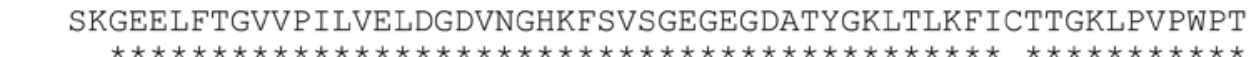 \\
\hline
\end{tabular}

AAA27721.1 60 LVTTFSYGVQCFSRYPDHMKQHDFFKSAMPEGYVQERTIFFKDDGNYKTRAEVKFEGDTL 119 4 EUL LVTT]Y YGVQCFSRYPDHMKQHDFEKSAMPEGYVQERTIFFKDDGNYKTRAEVKFEGDTL EGFPq LVTT TYTGVCFSRYPDHMK DHDFFKSAMPEGYVQERTIFFKDDGNYKTRAEVKFEGDTL GEPq LVTTRSYGVQCFSRYPDHMKRHDFFKSAMPEGYVQERTIFFKDDGNYKTRAEVKFEGDTL 2WUR LVTTSSYGQCFSRYPDHMKDHDFFKSAMPEGYVQERTIFFKDDGNYKTRAEVKFEGDTL 6JGI LVTTE

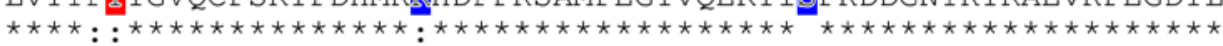

AAA27721.1 120 VNRIELKGIDFKEDGNILGHKLEYNYNSHNVYIMADKQKNGIKVNFKIRHNIEDGSVQLA 179 4EUL VNRIELKGIDFKEDGNILGHKLEYNYNSHNVYIMADKQKNGIKVNFKIRHNIEDGSVQLA EGFPq VNRIELKGIDFKEDGNILGHKLEYNYNSHNVYIMADKQKGGIKVNFK RHNIEDGSVQLA GFPq VNRIELKGIDFKEDGNILGHKLEYNYNSHNVYIMADKQKQGIKVNFK RHNIEDGSVQLA 2WUR VNRIELKGIDFKEDGNILGHKLEYNYNSHNVYIMADKQKNGIKVNFK RHNIEDGSVQLA

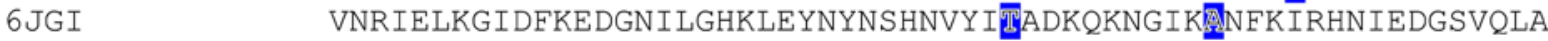

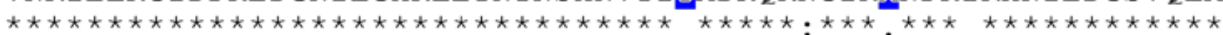

AAA27721.1 180 DHYQQNTPIGDGPVLLPDNHYLSTQSALSKDPNEKRDHMVLLEFVTAAGITHGMDELYK 4 EUL EGFPq GFPq

2WUR DHYQQNTPIGDGPVLLPDNHYLSTQSALSKDPNEKRDHMVLLEFVTAAGITRGMDELYK

$6 \mathrm{JGI}$ DHYOONTPIGDGPVLLPDNHYLSTOSALSKDPNEKRDHMVLLEFVTAAGITH DHYQQNTPIGDGPVLLPDNHYLSTQSALSKDPNEKRDHMVLLEFVTAAGITH DHYQQNTPIGDGPVLLPDNHYLSTQSALSKDPNEKRDHMVLLEFVTAAGITHGMDELY DHYQQNTPIGDGPVLLPDNHYLSTQSALSKDPNEKRDHMVLLEFVTAAGITH

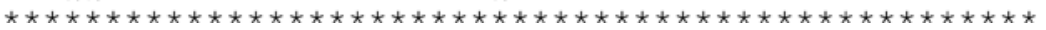

Figure S2. Amino acid sequence alignment of wild-type and mutant GFP proteins. The sequence number is shown on the both left and right sides. The proteins correspond to Genbank and PDB accession numbers AAA27721.1 [8], 4EUL [17], EGFPq and GFPq [this study], 2WUR[16], 6JGI[18], respectively. The mutation sites compared to the wild-type are indicated blue and red squares. 


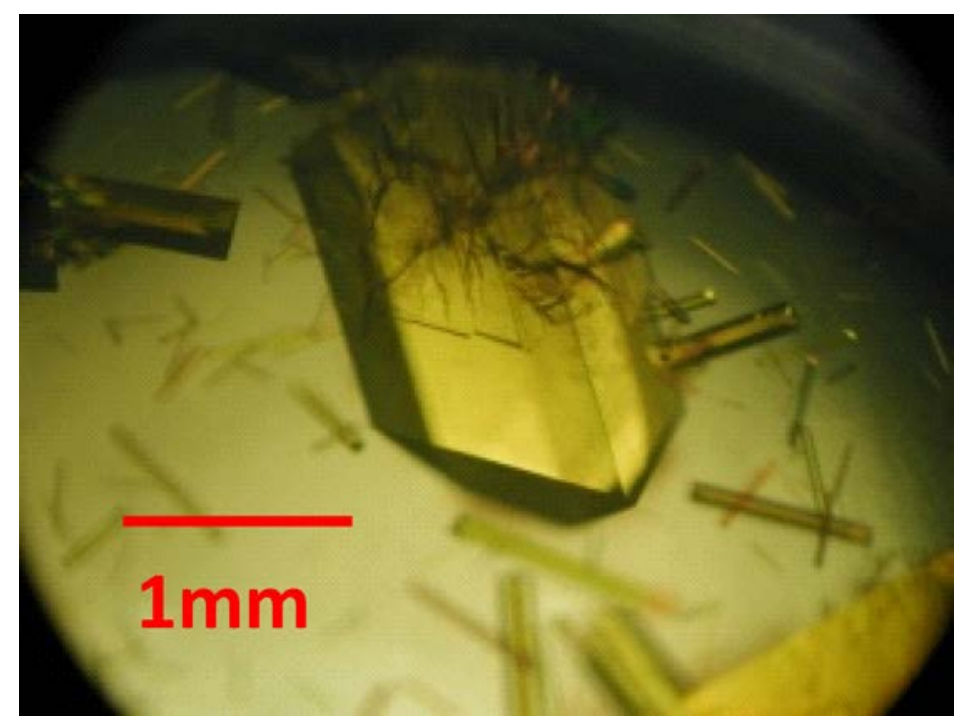

Figure S3. Photo of a large crystal of EGFPq used for neutron diffraction data collection at FRMII. The volume size was estimated to be $1.7 \mathrm{~mm}^{3}$. The large crystal was picked up without other smaller crystals by using cryo-loop for mounting at BioDIFF. 

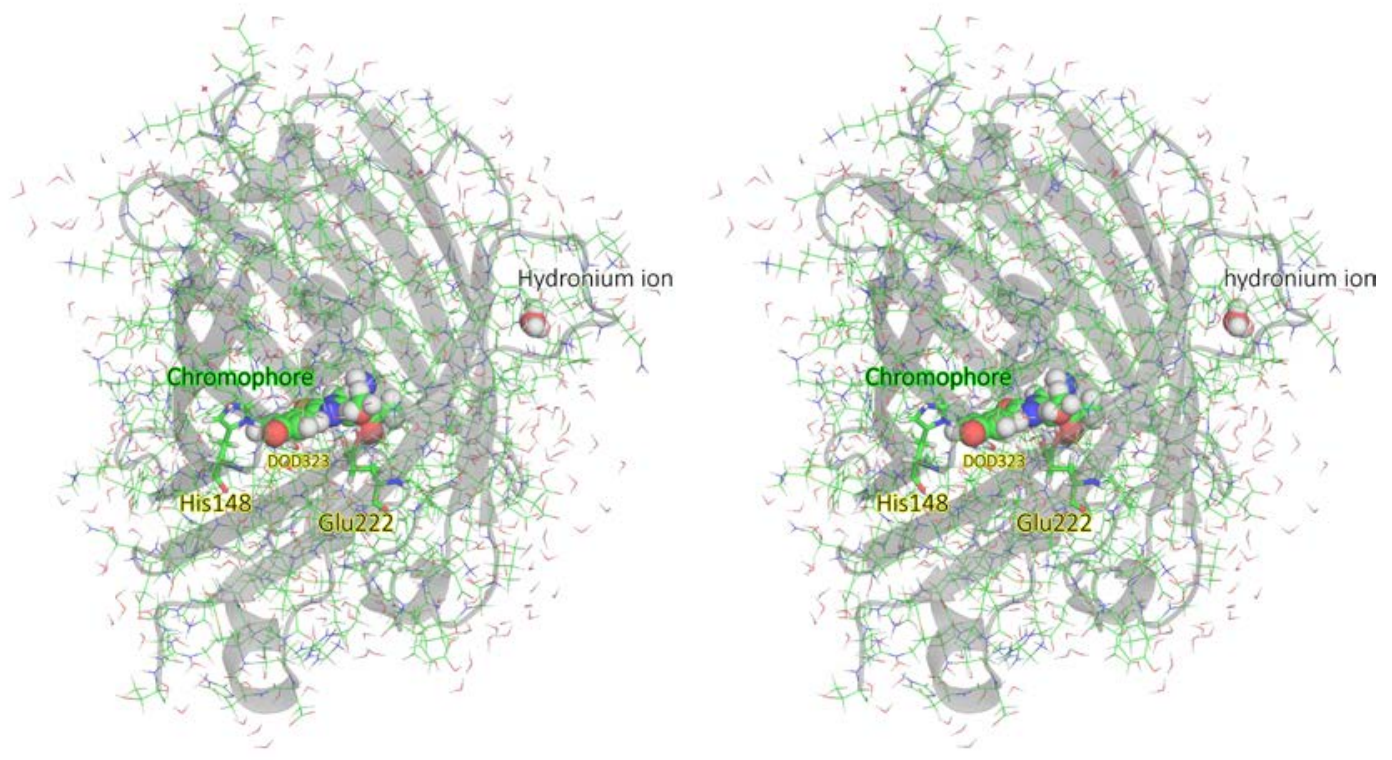

Figure S4. The tertiary structure of EGFPq determined by neutron crystallography (wall-eye stereo view). The overall protein molecule is shown as line and ribbon models. Chromophore and hydronium ion are shown by space-filling representation. The two key residues of His148 and Glu222, and the water molecule of DOD323 are drawn by stick model. Hydrogen and deuterium atoms are colored in gray. Carbon, oxygen, nitrogen, and sulfur atoms are colored in green, red, blue, and yellow, respectively. 

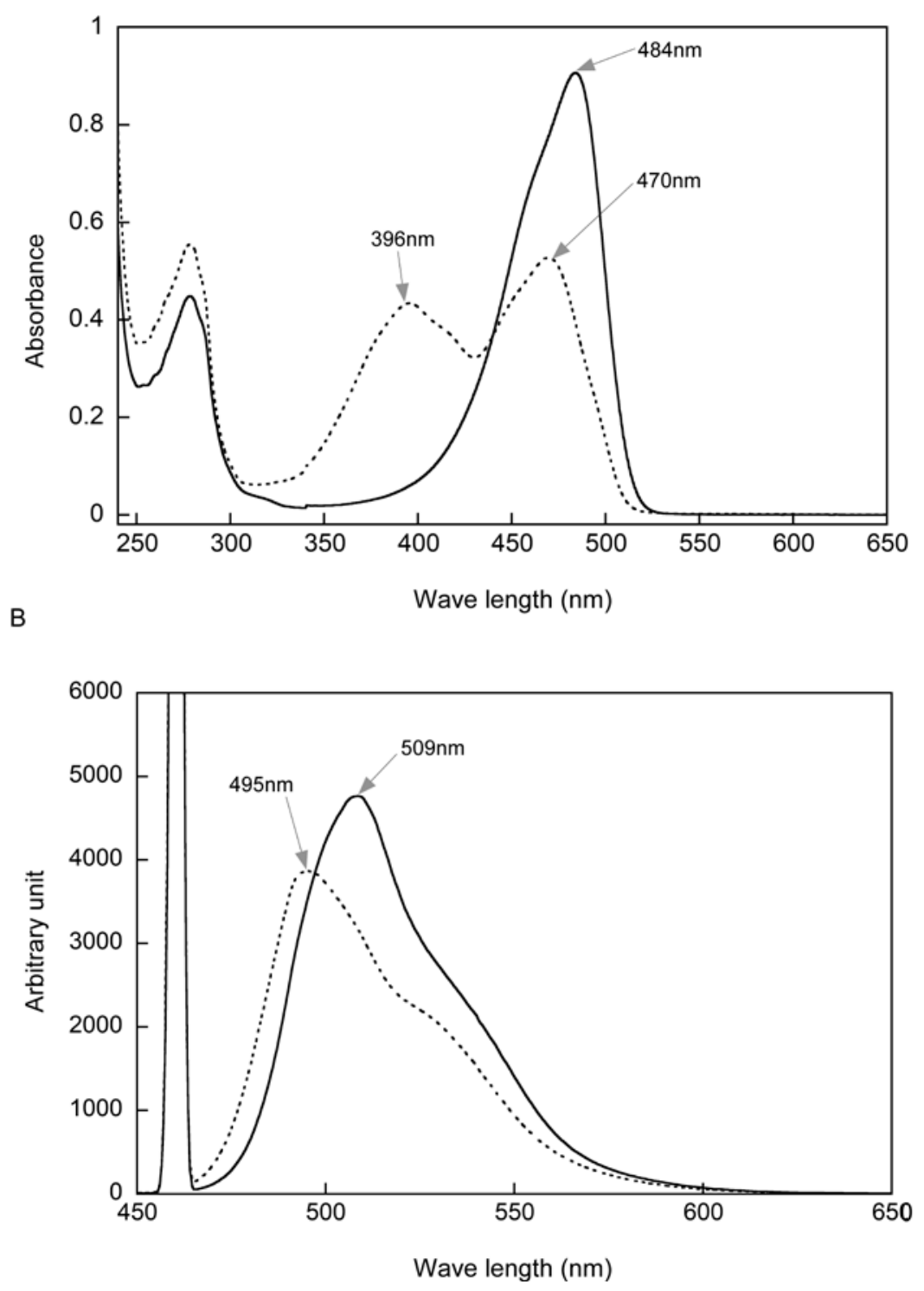

Figure S5. Absorption and fluorescent spectra of the EGFPq and GFPq. The proteins were dissolved in buffer (pH 8.0, $20 \mathrm{mM}$ TrisHCl) at $298 \mathrm{~K}$ for (A) and (B). Solid and dotted lines represent EGFPq and GFPq, respectively. Arrows indicate the peak positions with wavelength. 
A

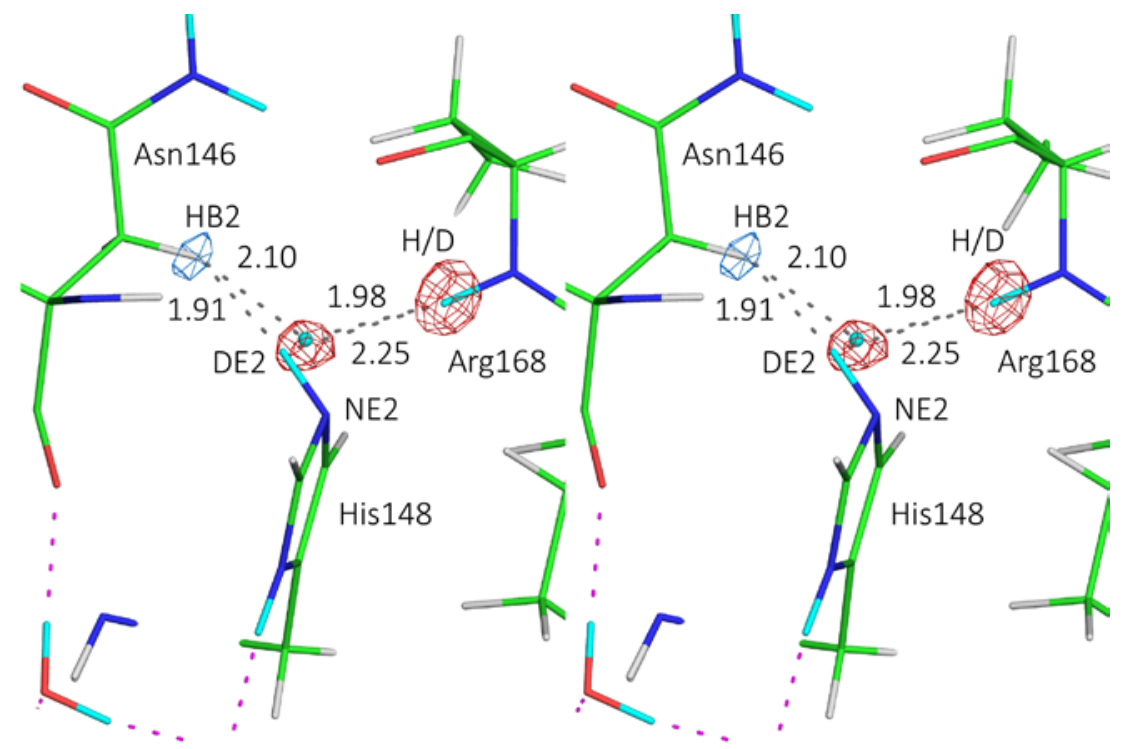

B

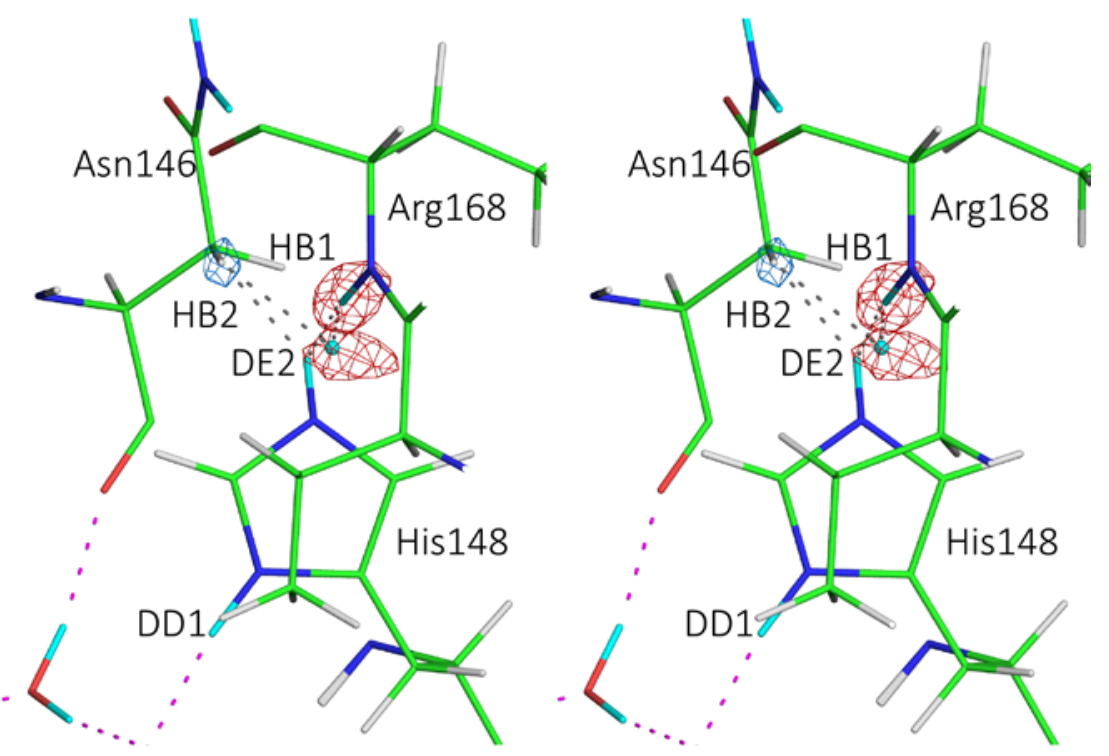

C

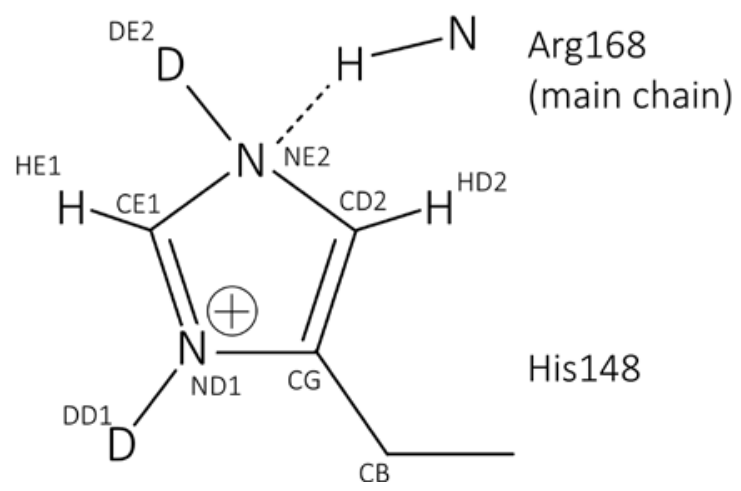


Figure S6. Neutron crystal structure of the His148 residue in EGFPq. (A) Bond model and neutron scattering length density maps are represented with stereo view. Hydrogen (light grey), deuterium (cyan), carbon (green), oxygen (red), nitrogen (blue) atoms are drawn. $F_{0}-F_{c}$ neutron omit maps are shown in red at $4 \sigma$ level for two deuterium atoms of DE2 in His148 and D in Arg168. $F_{\mathrm{o}}-F_{\mathrm{c}}$ neutron omit maps are shown in marine blue at $-4 \sigma$ level for the hydrogen atom of HB2 of Asn146. Bond distances are referred by grey dotted lines. The small bowl model indicates the position of DE2 atom in His148 after unrestrained refinement by changing restriction parameters including DE2 atom. The distance between HB2 in Asn146 and DE2 atom in His148 was increased by $0.19 \AA$, and the distance between D atom in Arg148 and DE2 atom in His148 were decreased by $0.27 \AA$ after the unrestrained refinement. The DE2 atom in His148 was moved by the unrestrained refinement in the distance of $0.42 \AA$. (B) The model of (A) was rotated by about 90 degree around the perpendicular axis. (C) Schematic drawing of the His148 residue. 
(A)
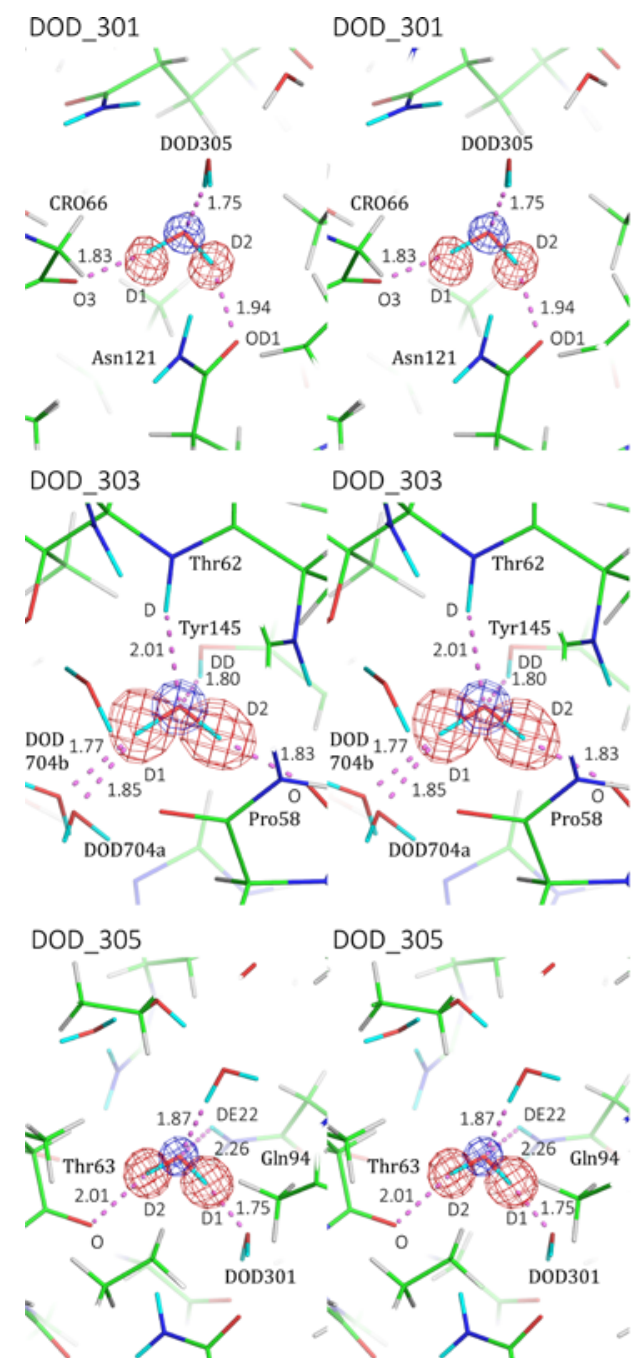

DOD 307

DOD 307
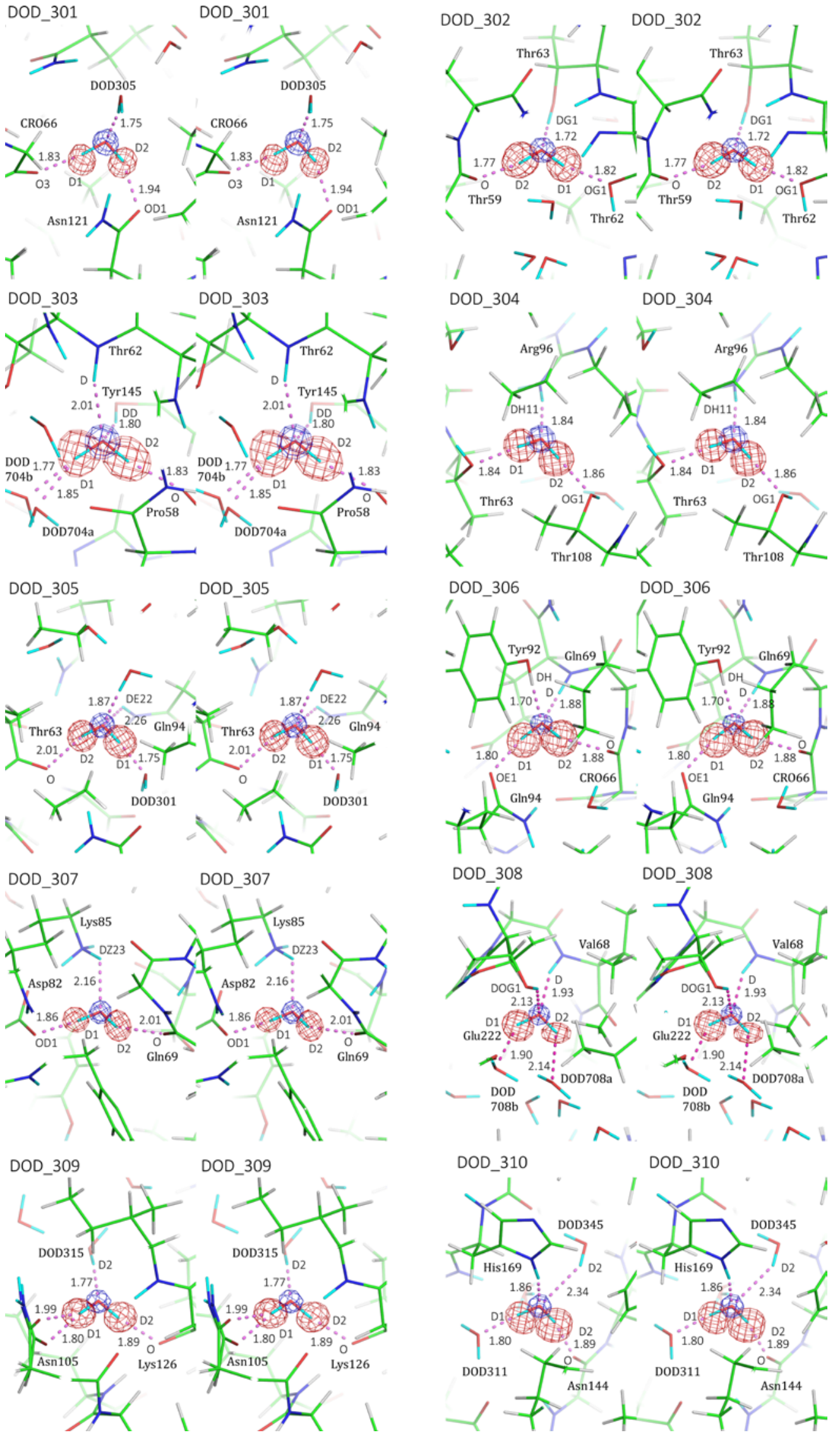
(B)
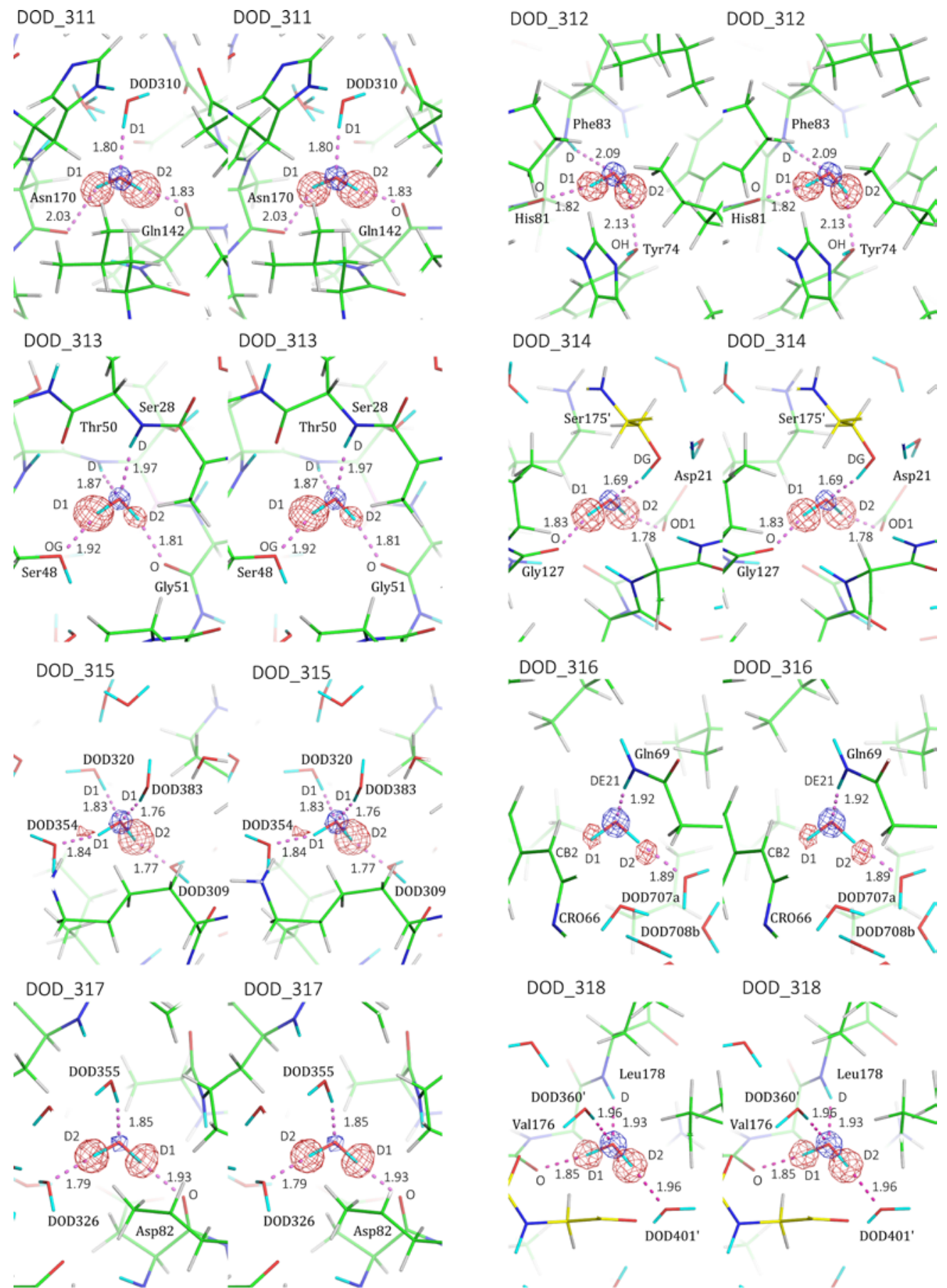

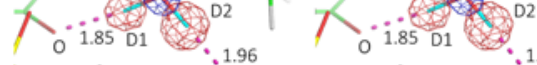
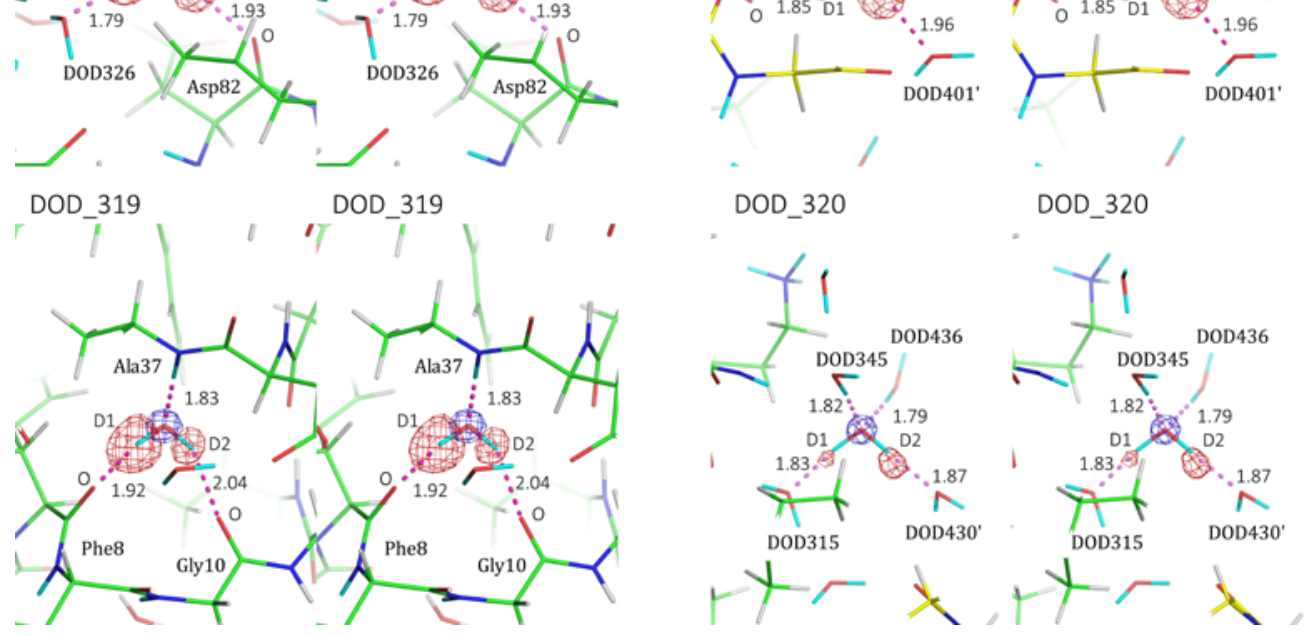
(C)
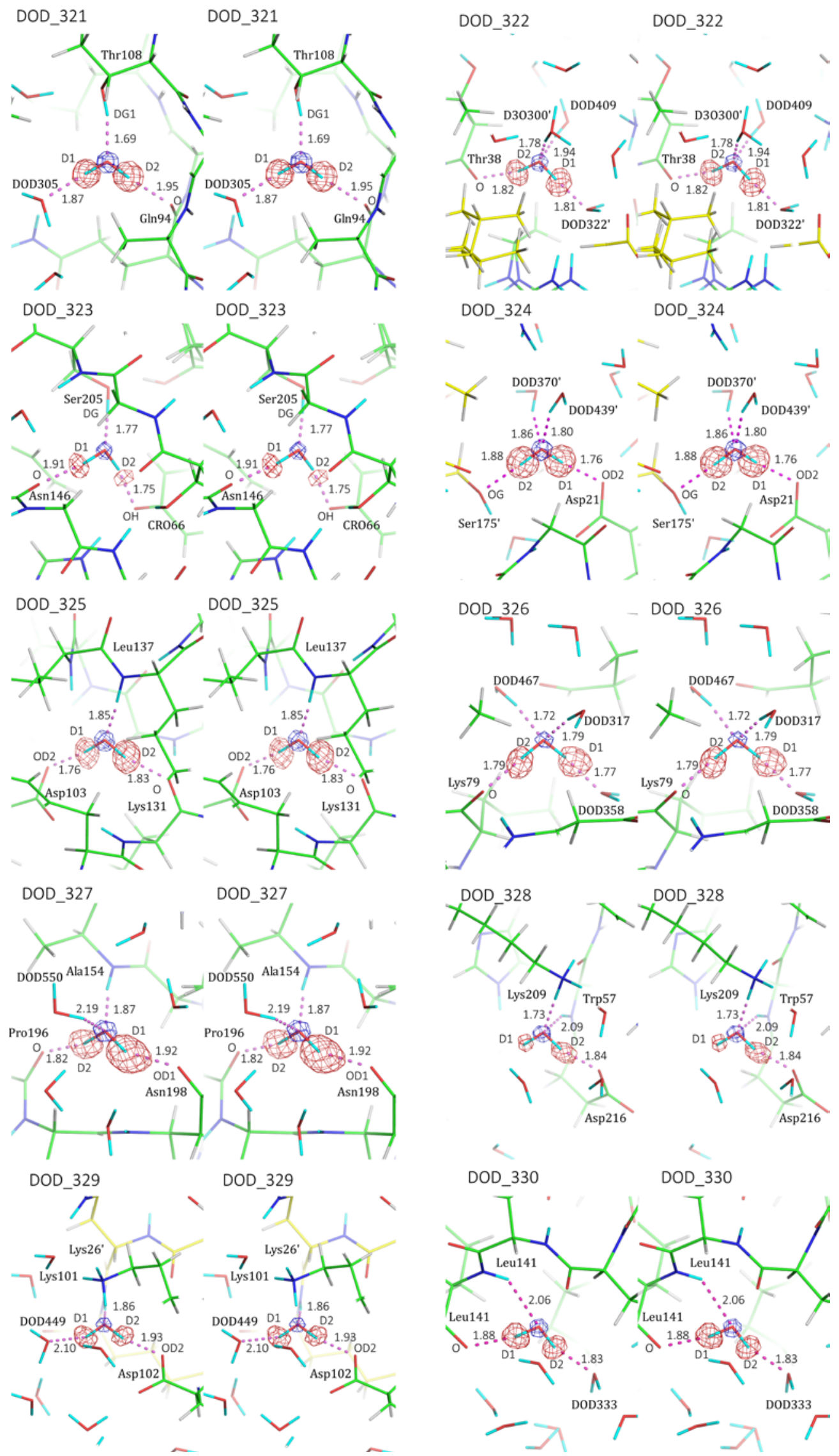
Figure S7. Neutron scattering density maps of deuterium atoms for thirty water molecules. Bond models are represented with stereo view. Hydrogen (light grey), deuterium (cyan), carbon (green), oxygen (red), nitrogen (blue) atoms are drawn by stick model. The carbon atoms in symmetrically generated models are drawn in yellow. $F_{0}-F_{\mathrm{c}}$ neutron omit maps for deuterium atoms and $2 F_{\mathrm{o}}-F_{\mathrm{c}} \mathrm{X}$-ray electron density maps in the thirty water molecules are shown in red and blue, respectively, at the $5 \sigma$ level. For the five atoms of DOD313_D2, DOD315_D1, DOD316_D2, DOD322_D1, and DOD323_D2, $F_{0}-F_{c}$ neutron omit are drawn at the $4 \sigma$ level. The thirty water molecules are selected on the basis of thermal factor of oxygen atom of water molecules refined without alternative structures, and are listed in Table S3. Hydrogen bonds are represented by dotted lines in magenta. (A), (B), and (C) include water molecules of DOD301-DOD310, DOD311-DOD320, DOD321-DOD330, respectively. The atom names and bond distances $(\AA)$ are shown by smaller letters. 
Table S1. Data collection and refinement statistics of neutron and X-ray crystallography.

\begin{tabular}{|c|c|c|c|}
\hline Protein & EGFPq (Thr65) & & GFPq (Ser65) \\
\hline Source & Neutron & $\mathrm{X}-$ ray $^{\S}$ & X-ray \\
\hline Solvent & $\mathrm{D}_{2} \mathrm{O}$ & $\mathrm{D}_{2} \mathrm{O}$ & $\mathrm{D}_{2} \mathrm{O}$ \\
\hline Collected beamline & BIODIFF at FRM II & BL5A at KEK-PF & BL5A at KEK-PF \\
\hline Wavelength $(\AA ̊)$ & 2.668 & 1.000 & 0.850 \\
\hline Temperature (K) & 100 & 100 & 100 \\
\hline Space group & $P 2_{1} 2_{1} Z_{1}$ & $P 2_{1} 2_{1} Z_{1}$ & $P 2_{1} 2_{1} 2_{1}$ \\
\hline Unit cell parameters & $\begin{array}{l}a=50.968 \AA \\
b=62.448 \AA \\
c=69.441 \AA\end{array}$ & $\begin{array}{l}a=50.857 \AA \\
b=62.160 \AA \\
c=69.202 \AA\end{array}$ & $\begin{array}{l}a=50.875 \AA \\
b=62.561 \AA \\
c=68.760 \AA\end{array}$ \\
\hline Resolution $(\AA)$ & 24.8-1.45 (1.49-1.45) & $46.2-0.88(0.91-0.88)$ & $28.5-0.77(0.80-0.77)$ \\
\hline No. of measured reflections & 90,310 & $1,354,518$ & $2,089,637$ \\
\hline No. of unique reflections & $35,569(2,069)$ & $164,854(15,558)$ & $258,331(25,594)$ \\
\hline Redundancy & $2.5(1.9)$ & $8.2(7.1)$ & $8.1(6.5)$ \\
\hline$R$-merge $(\%) \dagger$ & $9.8(27.7)$ & $5.3(32.8)$ & $6.7(74.0)$ \\
\hline Completeness of data (\%) & $88.9(73.8)$ & $95.0(90.3)$ & $100(100)$ \\
\hline I/ sig / & $7.9(2.4)$ & $66.9(6.4)$ & $61.45(2.8)$ \\
\hline \multicolumn{4}{|l|}{ Refinement } \\
\hline$R$-factor (\%) $\ddagger$ & 16.8 & 15.4 & 11.8 \\
\hline$R$-free $(\%) \ddagger$ & 20.7 & 16.5 & 12.4 \\
\hline RMSD bonds $(\AA ̊)$ & 0.012 & - & 0.015 \\
\hline RMSD angles (deg) & 1.389 & - & 1.587 \\
\hline Mean B value $(\AA ̊)$ & 19.6 & - & 9.9 \\
\hline PDBID & 6L26 & & $6 \mathrm{~L} 27$ \\
\hline
\end{tabular}

Values for highest-resolution shells are shown in the parentheses.

$\S X$-ray diffraction data were used for joint refinement.

$+R_{\text {merge }}=\Sigma|I-<|>|/ \Sigma<|>$

$\ddagger \mathrm{R}$-factor and $R_{\text {free }}=\Sigma|| F_{\mathrm{o}}|-| F_{\mathrm{c}}|| / \Sigma\left|F_{\mathrm{o}}\right|$, where the free reflections (5\% of total used) were held aside for $R_{\text {free }}$ throughout refinement. 
Table S2. Chemical bond lengths in chromophore for GFP proteins solved by high resolution $\mathrm{X}$-ray crystallography.

\begin{tabular}{|c|c|c|c|c|c|c|c|c|}
\hline & & & $\begin{array}{c}\text { EGFPq } \\
\left(T_{h r 65}\right)^{* 1}\end{array}$ & $\begin{array}{c}\text { GFPq } \\
(\operatorname{Ser} 65)^{* 2}\end{array}$ & $2 W \cup R^{* 3}$ & $4 \mathrm{EUL}^{* 4}$ & $\left.6 \mathrm{JG}\right|^{* 5}$ & $6 \mathrm{JGH} \mathrm{H}^{* 5}$ \\
\hline Chemical bond & $\begin{array}{c}\text { Atom } \\
1 \\
\end{array}$ & $\begin{array}{c}\text { Atom } \\
2 \\
\end{array}$ & $0.88^{* 6}$ & 0.77 & 0.90 & 1.35 & 0.85 & 0.94 \\
\hline \multirow[t]{4}{*}{ C-N } & $\mathrm{C} 1$ & N2 & $\begin{array}{r}1.290^{* 7} \\
3^{* 8}\end{array}$ & $\begin{array}{r}1.312 \\
1\end{array}$ & 1.292 & 1.32 & 1.306 & 1.295 \\
\hline & $\mathrm{C} 1$ & N3 & $\begin{array}{r}1.398 \\
3\end{array}$ & $\begin{array}{r}1.394 \\
1\end{array}$ & 1.401 & 1.32 & 1.398 & 1.395 \\
\hline & N2 & CA2 & $\begin{array}{r}1.405 \\
3\end{array}$ & $\begin{array}{r}1.402 \\
1\end{array}$ & 1.419 & 1.34 & 1.417 & 1.387 \\
\hline & N3 & $\mathrm{C} 2$ & $\begin{array}{r}1.374 \\
3\end{array}$ & $\begin{array}{r}1.367 \\
1\end{array}$ & 1.372 & 1.33 & 1.386 & 1.353 \\
\hline \multirow[t]{9}{*}{$\mathrm{C}-\mathrm{C}$} & $\mathrm{C} 2$ & CA2 & $\begin{array}{r}1.470 \\
3\end{array}$ & $\begin{array}{r}1.465 \\
1\end{array}$ & 1.454 & 1.42 & 1.448 & 1.444 \\
\hline & CA2 & CB2 & $\begin{array}{r}1.370 \\
3\end{array}$ & $\begin{array}{r}1.365 \\
1\end{array}$ & 1.392 & 1.43 & 1.369 & 1.375 \\
\hline & CB2 & CG2 & $\begin{array}{r}1.444 \\
3\end{array}$ & $\begin{array}{r}1.454 \\
1\end{array}$ & 1.412 & 1.42 & 1.431 & 1.438 \\
\hline & CG2 & CD1 & $\begin{array}{r}1.421 \\
5\end{array}$ & $\begin{array}{r}1.405 \\
1\end{array}$ & 1.427 & 1.40 & 1.406 & 1.409 \\
\hline & CG2 & $\mathrm{CD} 2$ & $\begin{array}{r}1.422 \\
3\end{array}$ & $\begin{array}{r}1.416 \\
1\end{array}$ & 1.377 & 1.41 & 1.417 & 1.391 \\
\hline & CD1 & CE1 & $\begin{array}{r}1.416 \\
3\end{array}$ & $\begin{array}{r}1.390 \\
2\end{array}$ & 1.344 & 1.40 & 1.372 & 1.368 \\
\hline & CD2 & CE2 & $\begin{array}{r}1.416 \\
3\end{array}$ & $\begin{array}{r}1.380 \\
1\end{array}$ & 1.385 & 1.38 & 1.364 & 1.396 \\
\hline & CE1 & $C Z$ & $\begin{array}{r}1.430 \\
5\end{array}$ & $\begin{array}{r}1.407 \\
1\end{array}$ & 1.412 & 1.40 & 1.429 & 1.397 \\
\hline & CE2 & $\mathrm{CZ}$ & $\begin{array}{r}1.418 \\
5\end{array}$ & $\begin{array}{r}1.394 \\
2\end{array}$ & 1.402 & 1.40 & 1.413 & 1.365 \\
\hline \multirow[t]{2}{*}{$\mathrm{C}-\mathrm{O}$} & $\mathrm{C} 2$ & $\mathrm{O} 2$ & $\begin{array}{r}1.233 \\
3\end{array}$ & $\begin{array}{r}1.247 \\
1\end{array}$ & 1.255 & 1.26 & 1.246 & 1.255 \\
\hline & $\mathrm{CZ}$ & $\mathrm{OH}$ & $\begin{array}{r}1.330 \\
3\end{array}$ & $\begin{array}{r}1.336 \\
2\end{array}$ & 1.324 & 1.35 & 1.314 & 1.365 \\
\hline
\end{tabular}

*1: The structure solved by neutron crystallography in this study (EGFPq; C48S, F64L, S65T, Q80R, N159Q, and 1167T). Slack value of $0.2 \AA$ was used in the unrestraint refinement for the bond distances listed above.

*2: The structure solved by X-ray crystallography in this study (GFPq; C48S, F64L, Q80R, N159Q, and I167T).

Slack value of $0.2 \AA$ was used in the unrestraint refinement for the bond distances listed above.

*3: Reference 16 .

*4: Reference 17.

*5: Reference 18.

*6: Resolutions (Å) for X-ray diffraction data are indicated.

*7: The bond lengths ( $(\AA)$ were listed.

*8: The standard deviations for the bond lengths $\left(10^{-3} \AA\right)$ were listed. The values were calculated as described in the section of Materials and Methods. 
Table S3. Bond distances in water molecules for EGFPq with restraint and unrestraint refinements by using slack value ${ }^{* 1}$.

\begin{tabular}{|c|c|c|c|c|c|c|c|c|c|c|}
\hline \multicolumn{3}{|c|}{ Water molecule } & \multicolumn{2}{|c|}{ Interacting residue } & \multicolumn{4}{|c|}{ Bond distance in the water molecule } & \multicolumn{2}{|c|}{ Hydrogen bond } \\
\hline Residue & $\begin{array}{l}\text { Atom } \\
\text { name }\end{array}$ & $\begin{array}{l}\text { Oxygen } \\
\text { atom }\end{array}$ & Residue & $\begin{array}{l}\text { Oxygen } \\
\text { atom }\end{array}$ & $\begin{array}{l}\text { Distance } \\
\text { with } \\
\text { restrain*2 }\end{array}$ & $\begin{array}{c}\text { Distance } \\
\text { without } \\
\text { restrain*3 }\end{array}$ & $\begin{array}{l}\text { Standard } \\
\text { deviation }{ }^{* 4}\end{array}$ & $\begin{array}{c}\text { Delta of } \\
\text { distance }\end{array}$ & $\begin{array}{c}\text { Bond } \\
\text { angle }\end{array}$ & Distance $^{* 7}$ \\
\hline \multirow[t]{2}{*}{ DOD301 } & $\begin{array}{c}\text { D1 } \\
(16.9)^{* 8}\end{array}$ & $\begin{array}{c}0 \\
(12.6)^{* 8}\end{array}$ & CRO66 & $\begin{array}{c}\text { O3 } \\
(12.5)^{* 8}\end{array}$ & 0.956 & 1.007 & 0.016 & +0.057 & 173.2 & $\begin{array}{l}2.78 \\
1.83 \\
\end{array}$ \\
\hline & $\begin{array}{c}\text { D2 } \\
(14.5)\end{array}$ & & Asn121 & $\begin{array}{c}\text { OD1 } \\
(12.8)\end{array}$ & 0.945 & 0.934 & 0.012 & -0.016 & 154.7 & $\begin{array}{l}2.82 \\
1.94\end{array}$ \\
\hline \multirow[t]{2}{*}{ DOD302 } & $\begin{array}{c}\mathrm{D} 1 \\
(13.1)\end{array}$ & $\begin{array}{c}0 \\
(12.8)\end{array}$ & Thr62 & $\begin{array}{c}\text { OG1 } \\
(12.8)\end{array}$ & 0.936 & 0.925 & 0.011 & -0.025 & 167.4 & $\begin{array}{l}2.74 \\
1.82\end{array}$ \\
\hline & $\begin{array}{c}\text { D2 } \\
(13.0)\end{array}$ & & Thr59 & $\begin{array}{c}0 \\
(13.1)\end{array}$ & 0.949 & 0.925 & 0.011 & -0.025 & 169.2 & $\begin{array}{l}2.71 \\
1.77\end{array}$ \\
\hline \multirow[t]{2}{*}{ DOD303 } & $\begin{array}{c}\mathrm{D} 1 \\
(16.2) \\
\end{array}$ & $\begin{array}{c}0 \\
(13.1) \\
\end{array}$ & DOD704a & $\begin{array}{c}0 \\
(13.9) \\
\end{array}$ & 0.938 & 0.886 & 0.022 & -0.064 & 160.6 & $\begin{array}{l}2.75 \\
1.84 \\
\end{array}$ \\
\hline & $\begin{array}{c}\mathrm{D} 2 \\
(16.7) \\
\end{array}$ & & Pro58 & $\begin{array}{c}0 \\
(13.8) \\
\end{array}$ & 0.944 & 0.927 & 0.024 & -0.023 & 163.5 & $\begin{array}{l}2.74 \\
1.82 \\
\end{array}$ \\
\hline \multirow[t]{2}{*}{ DOD304 } & $\begin{array}{c}\mathrm{D} 1 \\
(13.7) \\
\end{array}$ & $\begin{array}{c}0 \\
(13.2) \\
\end{array}$ & Thr63 & $\begin{array}{c}\text { OG1 } \\
(12.3)\end{array}$ & 0.950 & 0.931 & 0.015 & -0.019 & 169.6 & $\begin{array}{l}2.78 \\
1.84 \\
\end{array}$ \\
\hline & $\begin{array}{c}\mathrm{D} 2 \\
(13.7)\end{array}$ & & Thr108 & $\begin{array}{c}\text { OG1 } \\
(12.7)\end{array}$ & 0.950 & 0.952 & 0.013 & +0.002 & 175.8 & $\begin{array}{l}2.81 \\
1.86 \\
\end{array}$ \\
\hline \multirow[t]{2}{*}{ DOD305 } & $\begin{array}{c}\mathrm{D} 1 \\
(12.9)\end{array}$ & $\begin{array}{c}0 \\
(13.3)\end{array}$ & DOD301 & $\begin{array}{c}0 \\
(12.6)\end{array}$ & 0.958 & 0.972 & 0.015 & +0.022 & 167.9 & $\begin{array}{l}2.70 \\
1.75\end{array}$ \\
\hline & $\begin{array}{c}\text { D2 } \\
(14.7) \\
\end{array}$ & & Thr63 & $\begin{array}{c}0 \\
(12.4) \\
\end{array}$ & 0.958 & 0.981 & 0.013 & +0.031 & 158.9 & $\begin{array}{l}2.92 \\
2.01 \\
\end{array}$ \\
\hline \multirow[t]{2}{*}{ DOD306 } & $\begin{array}{c}\mathrm{D} 1 \\
(15.1)\end{array}$ & $\begin{array}{c}0 \\
(13.6) \\
\end{array}$ & $\mathrm{Gln} 94$ & $\begin{array}{c}\text { OE1 } \\
(13.4)\end{array}$ & 0.950 & 0.930 & 0.013 & -0.020 & 151.4 & $\begin{array}{l}2.68 \\
1.81 \\
\end{array}$ \\
\hline & $\begin{array}{c}\mathrm{D} 2 \\
(13.7) \\
\end{array}$ & & CR066 & $\begin{array}{c}\mathrm{O} 3 \\
(12.5) \\
\end{array}$ & 0.950 & 0.956 & 0.013 & +0.006 & 150.0 & $\begin{array}{l}2.74 \\
1.88 \\
\end{array}$ \\
\hline \multirow[t]{2}{*}{ DOD307 } & $\begin{array}{c}\mathrm{D} 1 \\
(15.4) \\
\end{array}$ & $\begin{array}{c}0 \\
(13.6) \\
\end{array}$ & Asp82 & $\begin{array}{c}\text { OD1 } \\
(13.4) \\
\end{array}$ & 0.956 & 1.009 & 0.014 & +0.059 & 172.7 & $\begin{array}{l}2.81 \\
1.86 \\
\end{array}$ \\
\hline & $\begin{array}{c}\text { D2 } \\
(14.4) \\
\end{array}$ & & Gln69 & $\begin{array}{c}0 \\
(12.6) \\
\end{array}$ & 0.950 & 0.925 & 0.020 & -0.025 & 147.2 & $\begin{array}{l}2.85 \\
2.01 \\
\end{array}$ \\
\hline \multirow[t]{2}{*}{ DOD308 } & $\begin{array}{c}\mathrm{D} 1 \\
(15.1)\end{array}$ & $\begin{array}{c}0 \\
(13.9)\end{array}$ & DOD708b & $\begin{array}{c}0 \\
(14.8)\end{array}$ & 0.943 & 0.893 & 0.016 & -0.057 & 137.3 & $\begin{array}{l}2.67 \\
1.90\end{array}$ \\
\hline & $\begin{array}{c}\text { D2 } \\
(16.2)\end{array}$ & & DOD708a & $\begin{array}{c}0 \\
(14.2)\end{array}$ & 0.956 & 1.019 & 0.021 & +0.069 & 132.5 & $\begin{array}{l}2.87 \\
2.14 \\
\end{array}$ \\
\hline \multirow[t]{2}{*}{ DOD309 } & $\begin{array}{c}\mathrm{D} 1 \\
(14.7)\end{array}$ & $\begin{array}{c}0 \\
(14.0)\end{array}$ & Asn105a & $\begin{array}{c}\text { OD1 } \\
(14.4)\end{array}$ & 0.947 & 0.940 & 0.011 & -0.010 & 166.3 & $\begin{array}{l}2.73 \\
1.80\end{array}$ \\
\hline & $\begin{array}{c}\text { D2 } \\
(14.8) \\
\end{array}$ & & Lys126 & $\begin{array}{c}0 \\
(13.3) \\
\end{array}$ & 0.953 & 0.941 & 0.011 & -0.009 & 168.2 & $\begin{array}{l}2.83 \\
1.89 \\
\end{array}$ \\
\hline \multirow[t]{2}{*}{ DOD310 } & $\begin{array}{c}\mathrm{D} 1 \\
(16.8) \\
\end{array}$ & $\begin{array}{c}0 \\
(14.2) \\
\end{array}$ & DOD311 & $\begin{array}{c}0 \\
(14.4)\end{array}$ & 0.947 & 0.888 & 0.015 & -0.062 & 172.1 & $\begin{array}{l}2.74 \\
1.80 \\
\end{array}$ \\
\hline & $\begin{array}{c}\mathrm{D} 2 \\
(17.0) \\
\end{array}$ & & Asn144 & $\begin{array}{c}0 \\
(14.3) \\
\end{array}$ & 0.953 & 1.024 & 0.016 & +0.074 & 166.7 & $\begin{array}{l}2.76 \\
1.82 \\
\end{array}$ \\
\hline \multirow[t]{2}{*}{ DOD311 } & $\begin{array}{c}\mathrm{D} 1 \\
(18.2)\end{array}$ & $\begin{array}{c}0 \\
(14.4)\end{array}$ & Asn170 & $\begin{array}{c}0 \\
(14.6)\end{array}$ & 0.952 & 0.947 & 0.018 & -0.003 & 150.8 & $\begin{array}{l}2.89 \\
2.02 \\
\end{array}$ \\
\hline & $\begin{array}{c}\text { D2 } \\
(14.9)\end{array}$ & & Glu142 & $\begin{array}{c}0 \\
(13.8)\end{array}$ & 0.954 & 0.956 & 0.012 & +0.006 & 169.8 & $\begin{array}{l}2.76 \\
1.82\end{array}$ \\
\hline \multirow[t]{2}{*}{ DOD312 } & $\begin{array}{c}\mathrm{D} 1 \\
(17.1)\end{array}$ & $\begin{array}{c}0 \\
(14.6)\end{array}$ & His81 & $\begin{array}{c}0 \\
(14.2)\end{array}$ & 0.943 & 0.925 & 0.016 & -0.025 & 160.8 & $\begin{array}{l}2.73 \\
1.82\end{array}$ \\
\hline & $\begin{array}{c}\text { D2 } \\
(18.2) \\
\end{array}$ & & Tyr74 & $\begin{array}{c}\mathrm{OH} \\
(13.4)\end{array}$ & 0.949 & 0.959 & 0.021 & +0.009 & 147.6 & $\begin{array}{l}2.98 \\
2.13 \\
\end{array}$ \\
\hline \multirow[t]{2}{*}{ DOD313 } & $\begin{array}{c}\mathrm{D} 1 \\
(17.0) \\
\end{array}$ & $\begin{array}{c}0 \\
(14.7) \\
\end{array}$ & Ser48 & $\begin{array}{c}\text { OG } \\
(15.0) \\
\end{array}$ & 0.955 & 1.048 & 0.019 & -0.098 & 157.5 & $\begin{array}{l}2.83 \\
1.92 \\
\end{array}$ \\
\hline & $\begin{array}{c}\mathrm{D} 2 \\
(18.9) \\
\end{array}$ & & Gly51 & $\begin{array}{c}0 \\
(16.8) \\
\end{array}$ & 0.941 & 0.815 & 0.026 & -0.135 & 167.1 & $\begin{array}{l}2.74 \\
1.81 \\
\end{array}$ \\
\hline \multirow[t]{2}{*}{ DOD314 } & $\begin{array}{c}\mathrm{D} 1 \\
(17.7) \\
\end{array}$ & $\begin{array}{c}0 \\
(14.8) \\
\end{array}$ & Gly127 & $\begin{array}{c}0 \\
(12.9) \\
\end{array}$ & 0.950 & 0.949 & 0.016 & -0.001 & 161.8 & $\begin{array}{l}2.75 \\
1.83 \\
\end{array}$ \\
\hline & $\begin{array}{c}\mathrm{D} 2 \\
(15.7)\end{array}$ & & Asp21 & $\begin{array}{c}\text { OD1 } \\
(14.1)\end{array}$ & 0.946 & 0.908 & 0.014 & -0.042 & 161.5 & $\begin{array}{l}2.70 \\
1.78 \\
\end{array}$ \\
\hline \multirow[t]{2}{*}{ DOD315 } & $\begin{array}{c}\mathrm{D} 1 \\
(26.7) \\
\end{array}$ & $\begin{array}{c}0 \\
(14.9) \\
\end{array}$ & DOD354 & $\begin{array}{c}0 \\
(18.0)\end{array}$ & 0.952 & 1.403 & 0.045 & +0.453 & 163.2 & $\begin{array}{l}2.76 \\
1.84 \\
\end{array}$ \\
\hline & $\begin{array}{c}\text { D2 } \\
(17.4)\end{array}$ & & DOD309 & $\begin{array}{c}0 \\
(14.0)\end{array}$ & 0.946 & 0.916 & 0.034 & -0.034 & 164.2 & $\begin{array}{l}2.70 \\
1.78\end{array}$ \\
\hline
\end{tabular}




\begin{tabular}{|c|c|c|c|c|c|c|c|c|c|c|}
\hline DOD316 & $\begin{array}{c}\text { D1 } \\
(19.8)\end{array}$ & $\begin{array}{c}0 \\
(15.1)\end{array}$ & - & $\begin{array}{l}- \\
(-)\end{array}$ & 0.944 & 0.792 & 0.020 & -0.158 & - & - \\
\hline & $\begin{array}{c}\text { D2 } \\
(19.6)\end{array}$ & & DOD707a & $\begin{array}{c}0 \\
(13.6)\end{array}$ & 0.958 & 1.112 & 0.026 & +0.162 & 171.4 & $\begin{array}{l}2.84 \\
1.88 \\
\end{array}$ \\
\hline \multirow[t]{2}{*}{ DOD317 } & $\begin{array}{c}\text { D1 } \\
(16.5)\end{array}$ & $\begin{array}{c}0 \\
(15.2)\end{array}$ & Asp82 & $\begin{array}{c}0 \\
(13.5)\end{array}$ & 0.954 & 0.990 & 0.015 & +0.040 & 167.5 & $\begin{array}{l}2.87 \\
1.93 \\
\end{array}$ \\
\hline & $\begin{array}{c}\text { D2 } \\
(17.0)\end{array}$ & & DOD326 & $\begin{array}{c}0 \\
(16.1)\end{array}$ & 0.953 & 0.964 & 0.019 & +0.014 & 173.2 & $\begin{array}{l}2.74 \\
1.79 \\
\end{array}$ \\
\hline \multirow[t]{2}{*}{ DOD318 } & $\begin{array}{c}\text { D1 } \\
(17.7)\end{array}$ & $\begin{array}{c}0 \\
(15.4)\end{array}$ & Val176 & $\begin{array}{c}0 \\
(14.7)\end{array}$ & 0.953 & 1.014 & 0.021 & +0.064 & 172.9 & $\begin{array}{l}2.80 \\
1.85 \\
\end{array}$ \\
\hline & $\begin{array}{c}\text { D2 } \\
(14.5)\end{array}$ & & DOD401' & $\begin{array}{c}0 \\
(22.1) \\
\end{array}$ & 0.936 & 0.875 & 0.015 & -0.075 & 158.8 & $\begin{array}{l}2.86 \\
1.97 \\
\end{array}$ \\
\hline \multirow[t]{2}{*}{ DOD319 } & $\begin{array}{c}\text { D1 } \\
(15.2)\end{array}$ & $\begin{array}{c}0 \\
(15.5)\end{array}$ & Phe8 & $\begin{array}{c}0 \\
(16.8)\end{array}$ & 0.950 & 1.009 & 0.016 & +0.059 & 165.8 & $\begin{array}{l}2.86 \\
1.93 \\
\end{array}$ \\
\hline & $\begin{array}{c}\text { D2 } \\
(17.2) \\
\end{array}$ & & Gly10 & $\begin{array}{c}0 \\
(16.5)\end{array}$ & 0.936 & 0.799 & 0.020 & -0.151 & 144.9 & $\begin{array}{l}2.84 \\
2.03 \\
\end{array}$ \\
\hline \multirow[t]{2}{*}{ DOD320 } & $\begin{array}{c}\text { D1 } \\
(23.1)\end{array}$ & $\begin{array}{c}0 \\
(15.5)\end{array}$ & DOD315 & $\begin{array}{c}0 \\
(14.9)\end{array}$ & 0.960 & 1.258 & 0.036 & +0.308 & 169.1 & $\begin{array}{l}2.78 \\
1.83 \\
\end{array}$ \\
\hline & $\begin{array}{c}\text { D2 } \\
(22.9)\end{array}$ & & DOD430' & $\begin{array}{c}0 \\
(25.0)\end{array}$ & 0.960 & 1.201 & 0.051 & +0.251 & 155.8 & $\begin{array}{l}2.76 \\
1.85 \\
\end{array}$ \\
\hline \multirow[t]{2}{*}{ DOD321 } & $\begin{array}{c}\text { D1 } \\
(17.4)\end{array}$ & $\begin{array}{c}0 \\
(15.5)\end{array}$ & DOD305 & $\begin{array}{c}0 \\
(13.3)\end{array}$ & 0.951 & 0.977 & 0.020 & +0.027 & 164.8 & $\begin{array}{l}2.80 \\
1.87\end{array}$ \\
\hline & $\begin{array}{c}\text { D2 } \\
(17.9)\end{array}$ & & $\mathrm{Gln} 94$ & $\begin{array}{c}0 \\
(13.1)\end{array}$ & 0.946 & 0.884 & 0.018 & -0.066 & 150.9 & $\begin{array}{l}2.81 \\
1.95 \\
\end{array}$ \\
\hline \multirow[t]{2}{*}{ DOD322 } & $\begin{array}{c}\text { D1 } \\
(24.1) \\
\end{array}$ & $\begin{array}{c}0 \\
(15.7) \\
\end{array}$ & DOD332' & $\begin{array}{c}0 \\
(16.6)\end{array}$ & 0.956 & 1.169 & 0.047 & +0.219 & 170.5 & $\begin{array}{l}2.76 \\
1.81 \\
\end{array}$ \\
\hline & $\begin{array}{c}\mathrm{D} 2 \\
(18.0)\end{array}$ & & Thr38 & $\begin{array}{c}0 \\
(14.7)\end{array}$ & 0.961 & 1.018 & 0.020 & +0.068 & 166.7 & $\begin{array}{l}2.76 \\
1.82 \\
\end{array}$ \\
\hline \multirow[t]{2}{*}{ DOD323 } & $\begin{array}{c}\text { D1 } \\
(18.3)\end{array}$ & $\begin{array}{c}0 \\
(15.8)\end{array}$ & Asn146 & $\begin{array}{c}0 \\
(15.6)\end{array}$ & 0.962 & 1.084 & 0.016 & +0.134 & 168.7 & $\begin{array}{l}2.87 \\
1.92 \\
\end{array}$ \\
\hline & $\begin{array}{c}\text { D2 } \\
(23.2) \\
\end{array}$ & & Cro66 & $\begin{array}{c}\mathrm{OH} \\
(15.1)\end{array}$ & 0.958 & 1.112 & 0.021 & +0.162 & 170.0 & $\begin{array}{l}2.71 \\
1.76 \\
\end{array}$ \\
\hline \multirow[t]{2}{*}{ DOD324 } & $\begin{array}{c}\text { D1 } \\
(18.7)\end{array}$ & $\begin{array}{c}0 \\
(15.9)\end{array}$ & Asp21 & $\begin{array}{c}\text { OD2 } \\
(16.7)\end{array}$ & 0.950 & 0.993 & 0.018 & +0.043 & 171.1 & $\begin{array}{l}2.71 \\
1.77 \\
\end{array}$ \\
\hline & $\begin{array}{c}\text { D2 } \\
(19.9)\end{array}$ & & Ser175' & $\begin{array}{c}\text { OG } \\
(14.1)\end{array}$ & 0.941 & 0.808 & 0.026 & -0.142 & 168.9 & $\begin{array}{l}2.81 \\
1.88\end{array}$ \\
\hline \multirow[t]{2}{*}{ DOD325 } & $\begin{array}{c}\mathrm{D} 1 \\
(17.0)\end{array}$ & $\begin{array}{c}0 \\
(16.0)\end{array}$ & Asp103 & $\begin{array}{c}\text { OD2 } \\
(16.9)\end{array}$ & 0.947 & 0.909 & 0.016 & -0.041 & 171.6 & $\begin{array}{l}2.70 \\
1.76 \\
\end{array}$ \\
\hline & $\begin{array}{c}\text { D2 } \\
(17.9)\end{array}$ & & Lys131 & $\begin{array}{c}0 \\
(18.6)\end{array}$ & 0.956 & 0.984 & 0.019 & +0.034 & 165.5 & $\begin{array}{l}2.76 \\
1.82 \\
\end{array}$ \\
\hline \multirow[t]{2}{*}{ DOD326 } & $\begin{array}{c}\text { D1 } \\
(19.4) \\
\end{array}$ & $\begin{array}{c}0 \\
(16.1)\end{array}$ & Lys79 & $\begin{array}{c}0 \\
(14.5)\end{array}$ & 0.954 & 1.009 & 0.031 & +0.059 & 177.1 & $\begin{array}{l}2.75 \\
1.79 \\
\end{array}$ \\
\hline & $\begin{array}{c}D 2 \\
(22.5)\end{array}$ & & DOD358 & $\begin{array}{c}0 \\
(18.5) \\
\end{array}$ & 0.961 & 1.305 & 0.029 & +0.355 & 173.9 & $\begin{array}{l}.73 \\
1.77 \\
\end{array}$ \\
\hline \multirow[t]{2}{*}{ DOD327 } & $\begin{array}{c}\text { D1 } \\
(17.6)\end{array}$ & $\begin{array}{c}0 \\
(16.3)\end{array}$ & Asn198 & $\begin{array}{c}\text { OD1 } \\
(18.0)\end{array}$ & 0.948 & 0.921 & 0.018 & -0.029 & 153.0 & $\begin{array}{l}2.78 \\
1.90\end{array}$ \\
\hline & $\begin{array}{c}\text { D2 } \\
(18.6)\end{array}$ & & Pro196 & $\begin{array}{c}0 \\
(15.6)\end{array}$ & 0.947 & 0.929 & 0.028 & -0.021 & 162.6 & $\begin{array}{l}2.74 \\
1.82\end{array}$ \\
\hline \multirow[t]{2}{*}{ DOD328 } & $\begin{array}{c}\text { D1 } \\
(21.5)\end{array}$ & $\begin{array}{c}0 \\
(16.3)\end{array}$ & & & 0.943 & 0.725 & 0.031 & -0.225 & - & - \\
\hline & $\begin{array}{c}\text { D2 } \\
(18.0)\end{array}$ & & Asp216 & $\begin{array}{c}\text { OD1 } \\
(15.1)\end{array}$ & 0.952 & 1.035 & 0.032 & +0.085 & 166.2 & $\begin{array}{l}2.77 \\
1.83 \\
\end{array}$ \\
\hline \multirow[t]{2}{*}{ DOD329 } & $\begin{array}{c}\mathrm{D} 1 \\
(18.7)\end{array}$ & $\begin{array}{c}0 \\
(16.4)\end{array}$ & DOD449 & $\begin{array}{c}0 \\
(27.6)\end{array}$ & 0.951 & 0.978 & 0.019 & +0.028 & 146.9 & $\begin{array}{l}2.92 \\
2.08 \\
\end{array}$ \\
\hline & $\begin{array}{c}\text { D2 } \\
(17.8)\end{array}$ & & Asp102 & $\begin{array}{c}\text { OD2 } \\
(21.6)\end{array}$ & 0.941 & 0.853 & 0.023 & -0.097 & 160.4 & $\begin{array}{l}2.85 \\
1.94\end{array}$ \\
\hline \multirow[t]{2}{*}{ DOD330 } & $\begin{array}{c}\text { D1 } \\
(16.5)\end{array}$ & $\begin{array}{c}0 \\
(16.5)\end{array}$ & Leu141 & $\begin{array}{c}0 \\
(15.5)\end{array}$ & 0.952 & 0.975 & 0.016 & +0.025 & 164.8 & $\begin{array}{l}2.81 \\
1.88 \\
\end{array}$ \\
\hline & $\begin{array}{c}\text { D2 } \\
(18.9)\end{array}$ & & DOD333 & $\begin{array}{c}0 \\
(16.5)\end{array}$ & 0.955 & 1.016 & 0.019 & +0.066 & 161.2 & $\begin{array}{l}2.76 \\
1.84\end{array}$ \\
\hline
\end{tabular}

*1: Slack value was incorporated for the unrestraint refinement of the two bond distances ( $\AA$ ) between oxygen and deuterium atoms in the water molecules. Thirty water molecules having lower B-factor value for oxygen atoms were selected and listed.

*2: Bond distances in water molecules of the final structure refined with restraint model.

*3: Average bond distances in water molecules were estimated after refinements by changing percentage of 
data for free R from 2.0 to $6.0 \%$ as described in the section of Materials and Methods, and by using slack value of $0.5 \AA$.

*4: The standard deviations for the bond lengths ( $(\AA)$ were listed. The values were calculated as described in the section of Materials and Methods.

*5: The difference of the bond distance between ideal (0.95 $\AA$ ) and unrestraint refinement values.

*6: Bond angles in the hydrogen bonds, for example, O(DOD301)-H1(DOD301)-O3(CRO66), are listed. The value of 180 degree indicates a hydrogen (deuterium) atom (D1 or D2) in water molecule locate on the line of hydrogen bond.

*7: Hydrogen bond distances between $\mathrm{O}$ atom in water molecule and an acceptor atom, and between deuterium atom (D1 or D2) in water molecule and an acceptor atom.

*8: Thermal factors are listed in the parentheses. 
Table S4. OH bond distances in hydronium ion and Glu17 for EGFPq refined by using slack value $^{* 1}$.

\begin{tabular}{|c|c|c|c|c|c|c|c|c|c|c|}
\hline \multicolumn{3}{|c|}{ Hydronium ion and Glu17 } & \multicolumn{2}{|c|}{ Interacting residue } & \multicolumn{4}{|c|}{ Bond distance in the water molecule } & \multicolumn{2}{|c|}{ Hydrogen bond } \\
\hline Residue & $\begin{array}{l}\text { Atom } \\
\text { name }\end{array}$ & $\begin{array}{c}\text { Oxygen } \\
\text { atom }\end{array}$ & Residue & $\begin{array}{c}\text { Oxygen } \\
\text { atom }\end{array}$ & $\begin{array}{l}\text { Distance } \\
\text { with } \\
\text { restrain*1 }\end{array}$ & $\begin{array}{l}\text { Distance } \\
\text { without } \\
\text { restrain }{ }^{* 2}\end{array}$ & $\begin{array}{c}\text { Standard } \\
\text { deviation } \\
*_{3}\end{array}$ & $\begin{array}{c}\text { Delta of } \\
\text { distance } \\
4\end{array}$ & $\begin{array}{c}\text { Bond } \\
\text { angle }^{* 5}\end{array}$ & Distance $^{* 6}$ \\
\hline \multirow[t]{3}{*}{ D30300 } & $\begin{array}{c}\text { D1 } \\
(21.8)^{* 7}\end{array}$ & $\begin{array}{c}0 \\
(18.7) \\
\end{array}$ & DOD322' & $\begin{array}{c}0 \\
(15.7)\end{array}$ & 0.987 & 0.964 & 0.034 & 0.018 & 173.6 & $\begin{array}{l}2.76 \\
1.78 \\
\end{array}$ \\
\hline & $\begin{array}{c}\mathrm{D} 2 \\
(26.1)\end{array}$ & & DOD336 & $\begin{array}{c}0 \\
(16.9) \\
\end{array}$ & 0.995 & 1.268 & 0.044 & 0.286 & 154.3 & $\begin{array}{l}2.72 \\
1.79 \\
\end{array}$ \\
\hline & $\begin{array}{c}\text { D3 } \\
(24.4)\end{array}$ & & DOD596 & $\begin{array}{c}0 \\
(34.9)\end{array}$ & 1.013 & 1.238 & 0.027 & 0.256 & 167.5 & $\begin{array}{l}2.56 \\
1.56\end{array}$ \\
\hline Glu17 & $\begin{array}{c}\text { DE2 } \\
(19.9)\end{array}$ & $\begin{array}{c}\text { OE2 } \\
(18.4)\end{array}$ & D30300 & $\begin{array}{c}0 \\
(18.7) \\
\end{array}$ & 0.943 & 0.894 & 0.020 & -0.054 & 156.3 & $\begin{array}{l}2.64 \\
1.75\end{array}$ \\
\hline
\end{tabular}

*1: The ideal distances for $\mathrm{OH}$ bonds in hydronium ion and Glu17 are configured to be 0.982 and $0.948 \AA$, respectively, in the restraint refinement.

*2: Slack value of $0.5 \AA$ was incorporated for the unrestraint refinement of the $\mathrm{OH}$ bond distances between oxygen and deuterium atoms in the hydronium ion (D30300) and hydroxyl group in the side chain in Glu17. Average bond distances were estimated after the refinements by changing percentage of data for free $\mathrm{R}$ from 2.0 to $6.0 \%$ as described in the section of Materials and Methods.

*3: The standard deviations for the bond lengths $(\AA)$ were listed.

*4: The difference of the bond distance between ideal and unrestraint refinement values.

*5: Bond angles in the hydrogen bonds are listed.

*6: Hydrogen bond distances between a donor and acceptor atoms, and between deuterium atom and an acceptor atom.

*7: Thermal factors are listed in the parentheses. 
Table S5. DNA primer sequences for EGFP and GFP mutants.

\begin{tabular}{|c|c|c|}
\hline Primer Name & DNA sequence & bp \\
\hline GFP_fu_N2 & $5^{\prime}$-GGAGATATACATATGGGCGAAGAACTTTTTACTGGCGTAGTC-3’ & 42 \\
\hline GFP_fu_C2 & $5^{\prime}$-ACCAGTCATGCTAGCTTAATGCGTAATTCCGGCTGCCGTTACAAAC - 3’ & 46 \\
\hline pET24a_fusion_F & $5^{\prime}$-GCTAGCATGACTGGTGGACAGCAAATGGGT - 3' & 30 \\
\hline pET24a_fusion_R2 & 5' - CATATGTATATCTCCTTCTTAAAGTTAAAC-3' & 30 \\
\hline GFP_C48S_F & 5’ -TTCATCAGCACAACAGGCAAATTACCGGTA-3’ & 30 \\
\hline GFP_C48S_R & 5’ -TGTTGTGCTGATGAATTTCAGGGTCAGTTT-3' & 30 \\
\hline GFP_N159Q_F & $5^{\prime}$ - CAGAAGCAGGGCATCAAAGTGAACTTTAAA-3' & 30 \\
\hline GFP_N159Q_R & 5’ -GATGCCCTGCTTCTGCTTATCCGCCATAAT - 3’ & 30 \\
\hline GFP_S65T_F & 5’ -ACGTTGACCTATGGCGTTCAGTGCTTTTCG-3’ & 30 \\
\hline GFP_S65T_R & 5' -GCCATAGGTCAACGTGGTAACGAGGGTCGG-3' & 30 \\
\hline
\end{tabular}

Under line indicates sequences overlapping with the paired primer. The mutation sites are shown in marine blue. Start and stop codons are shown in blue and red letters. 
Table S6. The coordinates obtained by the unrestraint refinement and displaced according to the neutron omit maps.

\begin{tabular}{|c|c|c|c|c|}
\hline Residue & Atom name & $x$ & $y$ & $z$ \\
\hline DOD323 & D1 $\left({ }^{*} 1\right)$ & 33.581 & 30.316 & -0.976 \\
\hline & $\mathrm{D} 2\left({ }^{*} 1\right)$ & 32.511 & 29.860 & 0.311 \\
\hline & $\left.\mathrm{D} 1{ }^{*} 2\right)$ & 33.601 & 30.419 & -0.976 \\
\hline & $\mathrm{D} 2\left({ }^{*} 2\right)$ & 32.512 & 29.848 & 0.520 \\
\hline His148 & $\mathrm{DE} 2\left({ }^{*} 1\right)$ & 34.688 & 35.565 & 0.474 \\
\hline
\end{tabular}

*1: The values were obtained by the unrestraint refinement.

*2: The positions were manually determined according to the neutron omit maps. 


\section{References}

34. Pace CN, Vajdos F, Fee L, Grimsley G, Gray T (1995) A How to measure and predict the molar absorption coefficient of a protein. Protein Sci 4(11): 2411-2423.

35. Otwinowski Z, Minor W (1997). Processing of X-ray diffraction data collected in oscillation mode. Meth Enzymol 276:307-326.

36. McRee DE (1992). A visual protein crystallographic software system for X11/XView. J Mol Graphics 10(1):44-46. 